\title{
A “ALEGRIA DO POVO”: CINEMA, ESPORTE, HERÓI*
}

\author{
"Joy of the People”: cinema, sport, hero \\ Lana Gomes Pereira** \\ Alexandre Fernandez Vaz ${ }^{* * *}$
}

\begin{abstract}
RESUMO
Trata o texto do filme Garrincha, alegria do povo, de Joaquim Pedro de Andrade, documentário cinemanovista em preto e branco sobre o ídolo do futebol brasileiro, lançado em 1963. Considerando algumas opções técnicas, políticas e estéticas dos realizadores, o trabalho tem como foco a análise de dois personagens centrais do filme, a saber, o próprio jogador e a torcida, ou o "povo" que ocupa as tribunas dos estádios. São analisadas algumas sequências, bem como aspectos da locução, momentos nos quais se materializa um discurso romântico simultaneamente associado ao futebol - o esporte moderno é expressão do Romantismo - e ao jogador Garrincha - exemplo de uma natureza "pura" e "indomável" a resistir aos ditames civilizadores. Com imagens da performance e da vida pública fora das quatro linhas de um dos atletas mais importantes do futebol brasileiro, o gênero cinema-verdade reconstrói e narra o mito. Este processo é interpretado sob a chave proposta pela leitura de uma dialética do esclarecimento, tal como propuseram
\end{abstract}

* O artigo é resultado parcial do programa de pesquisas Teoria Crítica, Racionalidades e Educação III, financiado pelo CNPq. Versões diferentes e preliminares em relação à presente foram previamente publicadas em Pereira e Vaz (2008) e Vaz e Pereira (2010).

** Professora da Universidade do Vale do Itajaí (UNIVALI), doutoranda em Science de L'Education, Université Paris 8 e no Programa de Pós-Graduação Interdisciplinar em Ciências Humanas, Universidade Federal de Santa Catarina (UFSC), Doutoranda. Membro do Núcleo de Estudos e Pesquisas Educação e Sociedade Contemporânea (UFSC/CNPq).

*** Programas de Pós-Graduação em Educação e Interdisciplinar em Ciências Humanas, Universidade Federal de Santa Catarina (UFSC). Coordenador do Núcleo de Estudos e Pesquisas Educação e Sociedade Contemporânea (UFSC/CNPq). Pesquisador do Conselho Nacional de Desenvolvimento Científico e Tecnológico (CNPq). 
Max Horkheimer e Theodor W. Adorno. Quanto à torcida, trata-se de mostrar a beleza dos corpos populares cujas dor e pobreza não estetizadas se encontram presentes na fotografia recheada de closes; o "povo" aparece em momento de lazer e júbilo pelas vitórias, mas também em sua contraface: a diversão como disciplina.

Palavras-chave: cinema brasileiro; Garrincha; documentário; herói; povo; mito; futebol.

\begin{abstract}
The papers aims to analyze the film Garrincha, alegria do povo, directed by Joaquim Pedro de Andrade. It's a white and black documentary of 1963, made inside the movement Brazilian New Cinema about the soccer idol. Observing some technical, political and aesthetically components of the film, the paper has as focus two actors: the soccer player Garrincha and the populars that act as fans in Stadium of Maracanã. Film sequences and speeches are analyzed, in that a romantic discourse shows up: sport has its origins in Romanticism and the player is an example of "pure" and "rebelling" nature against the civilization. With takes of soccer playing and of Garrincha's public life, the Direct Cinema constructs the myth. The proposes of Max Horkheimer and Theodor W. Adorno in Dialectic of Enlightenment offer the analytical schema to this process. The popular in the Stadium are showed in their corporal beauty, whose non aesthetically pain and poverty are objects of the closes: people are in their moment of leisure and celebration of victories, but also in their counterpart: funny as discipline.
\end{abstract}

Key-words: Brazilian cinema; Garrincha; documentary; hero; people; myth; Soccer.

\title{
1. Um cineasta e seu futebolista
}

Se fôssemos 75 milhões de Garrinchas, que país seria este, maior que a Rússia, maior que os Estados Unidos.

A epígrafe que abre este texto é de Nelson Rodrigues, provavelmente o maior dramaturgo brasileiro e um dos criadores da crônica jornalística dedicada ao futebol, mescla de informação, fantasia, ritual de forja 
da identidade nacional, dramatização épica e trágica de nossas glórias e mazelas. Junto com Mário Filho, seu irmão e autor do clássico estudo $O$ negro no futebol brasileiro, mas mais do que ele, Nelson emprestou forma trágica ao futebol, narrando-o, em tempos ainda com pouca transmissão televisiva, como acontecimento épico.

Escrito logo após a conquista do bicampeonato mundial de futebol pela seleção brasileira em 1962, no Chile, faz as vezes de abertura para o filme Garrincha, alegria do povo, concluído no ano seguinte como o primeiro documentário sobre o futebol brasileiro, realizado por uma equipe dirigida por Joaquim Pedro de Andrade. ${ }^{1}$ Garrincha, como era conhecido o futebolista profissional Manoel dos Santos, foi o principal nome daquela Copa, destacando-se nos momentos decisivos e assumindo a responsabilidade de suprir a ausência de Pelé, já então o jogador mais importante do mundo, contundido na segunda rodada e ausente no restante do certame.

O Botafogo de Futebol e Regatas, tradicional e vitorioso clube carioca, foi o principal clube em que atuou Garrincha. O time foi um dos grandes adversários do Santos Futebol Clube, em seu áureo período de glórias, durante os anos 1960, a era em que Pelé brilhou de forma incontestável no clube paulista. O Botafogo era um time de estrelas, atletas destacados. Nele jogara, por exemplo, Heleno de Freitas, nos anos 1940, um homem charmoso e diplomado em Direito, cuja fama de gênio irrequieto e craque boêmio teve como arremate a morte em um sanatório mineiro, por doença desencadeada pela sífilis. Heleno não pôde brilhar no Mundial de 1950, disputado no Brasil. Também no Botafogo jogariam nada menos que seis atletas que compuseram o plantel brasileiro presente na vitoriosa campanha da Copa do Mundo de 1970, no México, inclusive Gérson, o maestro do meio-campo. Garrincha, portanto, não foi o único, mas certamente o principal ídolo do Botafogo.

1 Joaquim Pedro de Andrade nasceu no Rio de Janeiro, em 25 de maio de 1932, e faleceu na mesma cidade, em 10 de setembro de 1988. Filho de Rodrigo Melo Franco de Andrade, fundador do Instituto do Patrimônio Histórico e Artístico Nacional - IPHAN, passou a infância em Minas Gerais e no Rio. Primo de Mário de Andrade e afilhado de crisma de Manuel Bandeira, sobre o qual realizou seu primeiro filme, Joaquim Pedro foi um dos principais representantes do Cinema Novo, tendo cumprido carreira cinematográfica importante e com relativo sucesso internacional. Em sua filmografia encontramos: O poeta do castelo (1959), O mestre de Apipucos (1959), Couro de gato (1961), Garrincha, alegria do povo (1963), O padre e a moça (1965), Cinema Novo (1966), Brasilia: contradições de uma cidade (1969), Macunaíma (1969), Os inconfidentes (1972), Guerra conjugal (1975), Vereda tropical (1977), O homem do pau-brasil (1981). 
Rodado em preto e branco, o filme de Joaquim Pedro sobre Garrincha reúne, em cerca de hora e meia, imagens de arquivos de alguns dos principais jogos do personagem, além de takes de treinos e do cotidiano do jogador, tanto na antiga Guanabara quanto em sua cidade natal, Pau Grande, Estado do Rio de Janeiro. A tessitura da narrativa do texto, de Armando Nogueira, Joaquim Pedro e Luiz Carlos Barreto (também um dos fotógrafos do filme), é entremeada por manifestações da torcida, por discreta trilha sonora, com destaque para uma mistura de ritmos e sons bem brasileiros, como sambas de duas Escolas tradicionais do Rio de Janeiro, Portela e Império Serrano, marchinhas que vangloriavam os heróis da época e pela música de Bach, bem como por silêncios que deixam protagonismo à montagem. Dito de outra forma é na construção das fotografias e imagens sobre este tempo/espaço que a ideia de montagem ganha status de personagem, dada a sua importância nesta construção.

No espírito do Cinema Novo, trata-se de reconhecer vida e dar voz a um herói "nacional-popular" (GRAMSCI, 1975), oriundo das camadas mais pobres da população e um dos grandes astros do esporte mais difundido no Brasil, mostrando-o constantemente como um presente da natureza, um mito a ser atualizado na narrativa cenográfica.

As estratégias metodológicas de Joaquim Pedro estão demarcadas não apenas pela escolha do tema e dos personagens do filme - o próprio Garrincha e o "povo" -, mas na opção pela câmera direta do cinema-verdade e pela montagem que se pretende "dialética", eisensteiniana (BENTES, 1996): a realidade sintetizada em cada quadro, uma imagem a se contrapor a outra. Para criar e dar sentido a este mosaico, como totalidade das representações, Carone Netto (1974) comenta que investir na montagem é desenvolver um específico encadeamento na narrativa. Isso significa oferecer à montagem a importância que já lhe dera Eisenstein (1990), como "propriedade orgânica" de todas as artes. É a intuição interior do autor, sua sensibilidade, que serão absorvidas por uma imagem que materializa efetivamente o tema (CARONE NETTO, 1974). A montagem em Garrincha, alegria do povo assume papel preponderante na narrativa, seja apresentando-nos, nas primeiras sequências, as jogadas de Garrincha e o entorno social que mitifica o nascimento do jogador, ou ainda evocando expressivos momentos de sua carreira e do próprio futebol brasileiro, grandes vitórias e fracassos exemplares.

Se um filme sobre esporte era uma novidade no Brasil, embora o tema tivesse aparecido em várias películas desde as primeiras décadas do 
século vinte (MELO, 2006), já os havia em bom número no mundo desde as experiências de Dziga Vertov (Polônia 1896-União Soviética 1954). Vertov é considerado o pai do Kino Pravda, correspondente ao que seria, no Brasil, o cinema-verdade. Suas experiências e estudos contribuíram na constituição da teoria do cinema, ao elaborar uma série de questões sobre a relação entre o olho da câmera e o evento a ser filmado. Em $O$ homem com uma câmera, mistura fotograma, narrativa e poesia para mostrar um cotidiano de Moscou captado por aquele aparato que é, segundo Benjamin (1977), o prolongamento do olho humano. Seu trabalho foi fundamental para o desenvolvimento do cinema direto nos anos de 1960, com o emprego de técnicas de filmagem específicas, a utilizaçao de câmeras leves e de som síncrono (IKEDA, 2009). Joaquim Pedro e sua equipe também tentaram, a partir do futebol, compreender certos elementos do cotidiano urbano na cidade do Rio de Janeiro, realizando uma montagem repleta de poesia, carregada de romantismo. ${ }^{2}$

Tratava-se, em Garrincha, não de qualquer esporte, mas do futebol e sua captação como elemento de produção e fruição populares, prática cultural na qual os heróis do espetáculo não eram nem os futebolistas das elites brasileiras do primeiro terço do século, nem os corpos brancos dos atores de Hollywood. Na tela estavam jogadores oriundos das camadas populares, de toda extração étnica, em movimentos que o Cinema Novo foi capaz de mostrar como belos, mas sem, no entanto, estetizar a dor e a pobreza encarnadas em cada rosto, em cada corpo.

As câmeras operadas por vários cinegrafistas coordenados pelo diretor de fotografia Mário Carneiro capturam imagens novas dentro e fora do campo de jogo, mas o fazem de forma diferente das lentes que compuseram o projeto de Riefenstahl, muito mais focado nos gestos esportivos individuais. A leveza dos equipamentos e o olhar politizado à esquerda

2 Outro projeto importante sobre esportes que antecede o de Joaquim Pedro é Olympia, famoso documentário dirigido pela alemã Leni Riefenstahl sobre os Jogos Olímpicos de 1936, que inaugura uma maneira de produzir imagens em movimento esportivo, captando-lhes, mas também lhes definindo, o caráter grandioso ou frustrante, épico e glorioso ou fracassado e mortificante do esporte. Também são conhecidas as incursões de Bertold Brecht sobre o tema, ele que era um entusiasta do pugilismo, modelo de comportamento do público para seu teatro revolucionário. O esporte era para Brecht uma possibilidade de propaganda e expressão do movimento operário comunista, de documentação - também ficcional - das experiências proletárias. O esporte como manifestação de grande importância e extensão seria a possibilidade, nos termos colocados brechtianamente por Benjamin (1977) no ensaio sobre a reprodutibilidade técnica da obra de arte, a possibilidade de a massa ver a si mesma. 
propiciaram outra procura no enquadramento: jogadores em seus corpos ágeis e habilidosos, mas de pernas tortas, como Garrincha; torcedores nas "gerais" do Estádio Mário Filho, o Maracanã, com seus olhos na altura do gramado do campo de jogo, expressões rugosas, mestiças, desdentadas. É o "povo", com toda carga de romantismo que aí se imprime, o segundo protagonista do filme.

Nas próximas páginas será feito um comentário sobre algumas sequências do filme referido, com foco nesses dois personagens que se mesclam, se realizam um com o outro, Garrincha e o "povo". Para tanto, citam-se e se interpretam aspectos do tema, da técnica e do contexto que o filme comporta, tentando verificar como dos personagens emergem as ambiguidades que lhes são próprias, mas que são também da narrativa retratos de um autor, de um tempo, de uma estética, de uma Nação, que anunciam a si mesmos por meio de Garrincha e a "alegria do povo", ainda que supostamente talvez nem sempre de forma deliberada.

\section{Ofilme e seu herói}

Garrincha, alegria do povo tem como um de seus eixos narrativos o ano de 1962, o da vitória da seleção brasileira de futebol na Copa do Chile, tempos de glória do jogador Garrincha. Pouco depois, inicia-se o período de seu declínio profissional, demarcado pela escassez de títulos nas temporadas seguintes, pelas constantes contusões e pela derrota na Copa de 1966, disputada na Inglaterra. O documentário trata da vida e das glórias do jogador no tempo presente, mas o herói construído por Joaquim Pedro é buscado em imagens do passado mítico que o futebol atualiza. Estão lá tanto o fracasso na Copa de 1950, a derrota frente ao Uruguai na final do certame para o qual o então maior estádio do mundo havia sido construído, quanto as vitórias frente aos europeus nos mundiais em que se consagra o Brasil campeão. Estão lá também as alterações corporais que eventualmente irrompem por entre as partidas de futebol, imagens dos duelos, como o contra o Uruguai na final do campeonato sul-americano de 1959, uma das diversas "vinganças" pelo Maracanazo, como ficou conhecida a derrota na final da 
Copa de 1950. Interessa ao diretor expor o futebol como ritual, e por isso se torna tão importante mostrar suas raízes populares no Brasil: a prática dos engraxates na praia, que abre o filme ao som de samba; Garrincha jogando uma "pelada" em Pau Grande, sem camisa e com os "verdadeiros amigos"; o povo indo e vindo ao estádio, santuário de celebração do entretenimento do final de semana, ciclo que se fecha, ao final da narrativa, com a volta de trem ao subúrbio.

\subsection{ENTRE MITO E ESCLARECIMENTO}

Em Garrincha, alegria do povo, observamos um futebol vindo de uma "natureza pura", cheia de dom ${ }^{3}$ e genialidade. Composto por operários fabris em torno de um momento que se supõe não disciplinar, caracterizado pela vida simples do popular protagonista - ídolo assediado no trem, nas ruas do centro do Rio de Janeiro, personagem de sambas e marchinhas, pai de sete meninas e ainda longe das controvérsias por sua união com a cantora Elza Soares - o futebol narrado no filme pertence a um "guerrilheiro de pernas tortas", como diz a locução. Essa mitologia, no entanto, é rivalizada pela origem do futebolista, vinculada ao tradicional futebol de fábrica. Segundo Leite Lopes (2006, p. 96):

Esse jogador, na verdade, é fruto de uma tradição operária de futebol amador, estimulada e praticada dentro de instituições esportivas geridas pelas fábricas ou empresas. Tudo indica que as empresas, especialmente industriais, desempenharam um papel importante na propagação do futebol no Brasil.

O filme de Joaquim Pedro não desconhece essa origem, mas opta por uma narrativa que confere peso ao talento desenvolvido fora do modelo de organização tradicional do esporte. Bartholo (2007), ao analisar a biografia mais conhecida de Garrincha - o livro de Ruy Castro (1995), Estrela solitária: um brasileiro chamado Garrincha - mostra como em torno do jogador se cria a aura de sua origem indígena geradora de um "bom

3 Sobre o dom como categoria nativa central no futebol, consultar Damo (2007). 
selvagem, de homem livre, ingênuo e espontâneo" (BARTHOLO, 2007, p. 66). De acordo com a discrição de Castro: "Vivia descalço - suas solas dos pés, desde sempre, eram as de quem andava no mato e nos calçados de pedra" (CASTRO, 1995, p. 27). Prevalece a imagem de que Garrincha se afirma desde cedo pela sua competência em jogar futebol, sem precisar de "esforço", característica esta popularmente atribuída aos desprovidos de competência técnica inata. Castro compara: "Garrincha era o nome de um passarinho indomável que não se acostumava ao cativeiro. Era uma espécie bem comum na região [...] Garrincha também não se adaptava ao cativeiro. Até os sete anos, sua vida foi caçar passarinhos, tomar banho no rio e jogar pelada" (CASTRO, 1995, p. 28).

Garrincha trabalhara desde os seus quinze anos, no final dos anos 1940, na rotina de uma fábrica em sua cidade natal. O que lhe teria valido o emprego teria sido o seu pertencimento ao seu time de futebol, mantido pela mesma empresa empregadora, visto que seria trabalhador indisciplinado. No momento em que o filme foi rodado, o jogador morava em uma casa ofertada pela sua antiga empregadora em uma vila operária. A residência foi-lhe cedida para seu usufruto perpétuo - portanto, sem posse definitiva - como prêmio pela conquista de 1962. Ao corpo indisciplinado da fábrica corresponde o corpo indomável pela lógica e rotina do treinamento esportivo: Garrincha é mostrado nos treinos do Botafogo a fazer repetições de exercícios tradicionais de condicionamento físico, mas a locução diz das denúncias das dificuldades com a balança e com o período de recolhimento antes dos jogos, da insuportável "concentração", do personagem como vítima preferencial de preparadores físicos e equipe clínica. Na trajetória de um futebolista de equipe de fábrica a um jogador de futebol profissional, Garrincha pouco mudaria. Continuava vivendo na cidade de Pau Grande, distante sessenta quilômetros do Rio de Janeiro, chegando aos treinamentos, segundo relata o filme, de trem ou ônibus, juntamente com torcedores e admiradores de seu futebol, e indo comemorar as vitórias com seus amigos em algum botequim, com muita cerveja. Diferentemente de Pelé, a quem foi comparado constantemente, sua ligação com o passado popular durou por muito tempo. Também foi fartamente caracterizado pelas suas emblemáticas pernas tortas. No filme, assistimos a um médico, diretor do Botafogo, que explica "cientificamente" as características dos membros inferiores do jogador. Entretanto, logo somos brindados com uma cena na qual surge a 
imagem de uma senhora que seria, além de lavadeira, capaz de benzer e curar, arrancando os gessos das pernas do craque, recuperando-o das mazelas oriundas das frequentes contusões. ${ }^{4}$ A tal ponto estaria "naturalizada" a sua condição corporal que, segundo Leite Lopes (2006), Garrincha teria se dado conta das pernas tortas apenas pela leitura dos jornais.

No trânsito entre mito e esclarecimento, processo imemorial de edificação da racionalidade, oscilante, ambíguo, mas em direção conhecida, conforme sugerem Horkheimer e Adorno (1997), e sempre na perspectiva de construção do herói, não há dúvidas sobre a opção narrativa: o futebol é expressão mitológica materializada em um corpo que, romanticamente, se mantém indômito: numa das primeiras sequências do filme, assiste-se ao jogador sendo marcado, depois parado com faltas, logo após torna-se impossível detê-lo, então ele leva o Botafogo ao título carioca de 1962. Por outro lado, não apenas a benzedeira seria mais importante que o médico, mas todo o selecionado brasileiro de 1962 teria recusado novos uniformes cedidos por uma alfaiataria italiana, preferindo as surradas camisetas com as quais havia vencido partidas recentes.

O esporte tem raízes românticas, uma malograda tentativa de devolver ao corpo uma porção de natureza que lhe haveria roubado o trabalho (ADORNO, 1997), momento de mal-estar cultural na procura de reconversão de um corpo anatômico - Körper - a um corpo com vida - Leib (HORKHEIMER; ADORNO, 1997). Joaquim Pedro aposta suas fichas, investe no discurso romântico ao valorizar a espontaneidade do gesto, ao fazer o elogio da malandragem e da pureza que supõe emergir do futebol, arte popular a ser documentada e celebrada.

O filme constrói o herói romântico e mítico Garrincha. São planos frequentemente urdidos pela aceleração da fotografia, pela montagem com cortes em diferentes tempos, por uma locução apologética e com a adição

4 Outro episódio que compõe o personagem e sua trajetória é o da sua morte e enterro. Nos últimos anos de vida, o jogador passa por uma rotina de hospitalizações causadas pela dependência ao álcool. Manuel Francisco dos Santos é encontrado morto após um coma alcoólico com o nome na ficha do Hospital de Manuel da Silva, uma variante próxima do anônimo "José da Silva" (LEITE LOPES, 2006). Como que para pagar esta dívida com o jogador, a mídia se mobiliza divulgando com muita rapidez a morte da "Alegria do Povo". O cortejo fúnebre, o velório (no Maracanã) e o enterro receberam centenas de torcedores e amantes do futebol, ultrapassando em muito as expectativas dos organizadores. Com um pomposo caixão, Garrincha foi enterrado na sua cidade natal, processo articulado por seu padrinho e companheiro de futebol Nilton Santos (LEITE LOPES, 2006). 
de som de estúdio, já que, como lembra Bentes (1996), a captação não pôde ser feita com som direto.

Em uma sequência logo no início da película, o diretor e sua equipe utilizam imagens da final do campeonato carioca de futebol. Garrincha joga pelo Botafogo e vemos seus dribles filmados de vários ângulos, ${ }^{5}$ com aproximações, close-ups que captam os movimentos, sobretudo seu principal trunfo: o drible pela direita. Do jogador com incrível capacidade de aceleração, Joaquim Pedro de Andrade e sua equipe não perdem oportunidade de compor quadros a partir de planos médios e americanos, das jogadas vistas das gerais, das arquibancadas, usando e abusando dos movimentos originários da câmera.

O estádio é descrito em imagens com complexos movimentos de câmeras que giram, aproximam-se e distanciam-se para que tenhamos a impressão da sua grandeza. Novamente, na sequência, close-ups e aproximações compõem o quadro das pernas tortas do jogador. $\mathrm{O}$ segundo personagem, o povo, na forma de torcida, é captado em suas expectativas, ansiedades, rostos, gestos, expressões de comemoração ou de descontentamento. Logo após, há um investimento nos lances do herói, seus dribles pela direita, impulsão, corridas, tentativas de gols a partir de planos médios e americanos, explorados pela câmera olho de Joaquim Pedro e sua equipe. Raramente conseguimos acompanhar a finalização de uma jogada, já que é a forma de movimentação de Garrincha, com suas pernas tortas se deslocando no espaço, que interessa ao diretor. Uma série de fotos de Garrincha, de alguns jogadores e de quedas intercala-se com fotos do jogador no chão. Imagens das dificuldades dos jogadores de escaparem dos dribles desconcertantes de Garrincha despertam a ira nos seus adversários que, sem outras opções, derrubam-no. Após as quedas, uma belíssima sequência de gols de

5 Ângulo é a região de um plano concebida pela abertura de duas semirretas que possuem uma origem em comum (vértice do ângulo), dividindo este plano em duas partes. Aproximação diz respeito ao movimento da câmera deslocando-se para aproximar-se de uma personagem ou objeto. Para compor-se um quadro cinematográfico utiliza-se como terminologia (ainda que duvidosa) "planos". O primeiro plano, também conhecido como close-up, é uma câmera que recorta o rosto da personagem, este em geral fica mais ou menos do ponto de vista teatral. Dar ênfase à personagem e recortá-la da cintura para cima, mas também valorizando o espaço e o cenário, é o que chamamos de plano médio. O plano americano enquadra a personagem do joelho para cima, facilitando seu reconhecimento. É assim denominado porque foram os norte-americanos os que primeiro utilizaram este estilo, nos anos 1940 e 1950, principalmente nos filmes de faroeste, em que era preciso mostrar a expressão do personagem e a arma que ele carregava na cintura (LEONE, 2005). 
Garrincha e a comemoração do povo na arquibancada. Joaquim brinca com a velocidade da filmagem e o estado de euforia dos torcedores do Botafogo é ampliado até o êxtase.

Em outra sequência, observamos fragmentos de jogos das Copas de 1962 e 1958, quando a montagem de Joaquim Pedro e Nello Melli privilegia as performances de Garrincha e Pelé. A entrada em campo das equipes do Brasil e do México deixa-se explorar por diversos ângulos, para serem captadas em planos americanos. O estádio Viña del Mar torna-se palco de jogadas pelos dois flancos, com lances de êxito e erros. Desprezando a ordem cronológica, assistimos a imagens do jogo Brasil X Espanha, intercaladas com jogadas bem-sucedidas de Garrincha e com notícias de manchetes de jornal que elogiam o desempenho da equipe brasileira e destaque para os inusitados episódios vividos por Garrincha.

Finalizando a sequência, a equipe de Joaquim utiliza as imagens do emocionante jogo do Brasil contra a Suécia, final do Mundial de 1958. A narração descreve as mazelas da equipe brasileira de ter como destino a derrota em jogos finais, que seria fruto de desequilíbrio emocional. No início do jogo, é confirmada a tese da narração e vemos em planos americanos e médios os suecos numa única jogada de seis perfeitos passes finalizarem com um gol, sem que nenhum jogador brasileiro houvesse tocado na bola. Após esse revés, a equipe inicia uma sequência de jogadas e principalmente Garrincha se destaca, realizando inúmeros e repetitivos dribles pelo lado direito, conduzindo bolas pelo meio campo, deixando para trás todos os "Joões", como Garrincha se referia aos seus marcadores, aos que cruzavam seu caminho. Na Copa do Chile, o herói construído pela narrativa do filme procura revelar um guerrilheiro indomável. Ele teria desobedecido ao treinador ao não se restringir à ponta-direita, deslocando-se pelo campo todo, e bateu uma falta, suplantando o especialista Didi, marcando gol com um chute de uma improvável perna esquerda. Ainda seria expulso, mas voltaria na partida seguinte - a final - porque a pressão por sua presença teria incluído até mesmo o presidente do Peru, país do árbitro que o havia expulsado, encantado com sua performance.

Durante as duas sequências, escutamos gritos de uma catártica torcida, ora comemorando, ora descarregando a raiva oriunda de alguma suposta injustiça do árbitro ou inconformismo com os destinos do jogo. É quando se sincronizam som e imagem, tanto as captadas no campo quanto 
as de arquivo dos jogos da seleção, ou ainda as estáticas fotografias, que ganham uma dinâmica muito própria na montagem. Tempo e espaço se fundem e se recriam nas elipses e flashbacks operados pela colagem que mostra Garrincha como herói que se forja numa não temporalidade que é a própria expressão romântico-fundadora nacional: corpo mítico, hábil por natureza, puro e rebelde, mestiço, malandro, terceiro-mundista, anti-holywoodiano (BENTES, 1996).

\title{
3. O "povo" como torcida e espectador
}

\begin{abstract}
"Garrincha, alegria do povo", documentário sobre o futebol brasileiro, é antes de tudo visão do povo, do amor do povo, da miséria, da alegria, da superstição e da grandeza do povo na figura do menino das pernas tortas, que é o improviso do povo. (Glauber Rocha, 2003, p. 149).
\end{abstract}

O comentário não deixa dúvidas sobre o segundo personagem do filme, o já mencionado "povo", "uma multidão inumerável de homens semelhantes e iguais, que sem descanso se voltam sobre si mesmos, à procura de pequenos e vulgares prazeres, com os quais enchem a alma", como se escuta na voz de Heron Domingues, o narrador do filme. Garrincha e ele entrelaçam-se, misturam-se, identificam-se. As imagens do povo nas gerais e arquibancadas e o futebol de Garrincha no campo se encontram a todo o momento no filme. Em rostos, sorrisos, choros, gritos, formas, o povo se vê nos pés do ídolo e em seus dribles pela direita, em suas jogadas desconcertantes, em seus gols. É como se materializasse a exigência decifrada por Benjamin (1977) para o cinema como expressão moderna e revolucionária da união entre técnica e estética: $o$ direito de ser filmado.

A exposição de Garrincha perante a multidão, no estádio ou na rua, é também a sua revelação diante da máquina que filma, mas não ainda na forma de ser cada jogador um ator, como hoje, quando cada qual sabe que poderá ser filmado, a qualquer e a todo momento do jogo, antes ou depois dele (RIAL, 2003). 
Lembre-se que o esporte-espetáculo se realiza, sobretudo, para ser captado como imagem. O jogador representa a si mesmo nas partidas de futebol perante, especialmente, os torcedores, mas essa representação tende à arte popular, circense, por meio de dribles singulares, únicos, compostos de elementos que talvez façam viver o momento de jogo, lúdico, mesmo dentro das asperezas do esporte competitivo, profissional. O jogador representa um futebol arte-popular, analisado pelos torcedores - esses semiespecialistas, poderia ter dito Benjamin (1977), inspirado em Brecht -, aprovado ou reprovado por eles. A todo tempo na película vê-se reafirmada a paixão do brasileiro pelo futebol. Os corpos, em especial os rostos em close-up mostrados nas arquibancadas, falam: os olhares atentos, os gestos de nervosismo, as bocas e expressões de espanto e medo, o riso, o choro, a raiva, a euforia e, às vezes, a decepção.

A câmera da equipe de Joaquim, numa outra sequência, com planos americanos e close-ups, nos mostra a chegada do povo ao santuário do futebol: o estádio. Os rostos filmados mostram um povo sem maquiagem, sem cuidados especiais, sem camuflagem. Vemos o grotesco se fazendo presente nos gestos, expressões, gritos e palavrões. O povo, o popular, o puro e o impuro, com sua carga de romantismo, não deixa de mostrar-se nas contradições, quando o sofrimento é confortado pelos dribles de Garrincha que submetem os adversários. A apoteose da torcida se manifesta na comemoração eufórica com a vitória do Brasil, saltos de alegria, gritaria, abraços e uma filmagem que ora acelera, ora diminui a velocidade das imagens, reforçando o caráter de êxtase, a emoção e a beleza. $\mathrm{O}$ rádio de pilha junto aos ouvidos dos torcedores é focalizado, amantes do futebol que não prescindem da narrativa oral para que não se perca qualquer episódio de uma partida.

Nessa sequência, pela primeira vez, aparece a torcida. São os instantes que precedem a partida e neles se vê a antessala dos acontecimentos: jogadores se preparando, os torcedores já presentes nas arquibancadas e nas antigas gerais. É notória a espera ansiosa pelo início da partida, mesmo com chuva. Jogo terminado, Botafogo campeão, Joaquim Pedro mostra a festa no campo com Garrincha e a equipe, intercalando imagens da alegria do povo. As tomadas em velocidade lenta dão a impressão de leveza e durabilidade, ao passo que, ao vermos a festa da torcida sendo filmada de forma acelerada, temos a sensação de euforia, enlouquecimento, paixão. Os closes 
feitos por Joaquim mostram o "povo": rostos retorcidos, caretas, olhares atentos, testas franzidas, sorrisos, gritos, bocas abertas, corpos magros, maltratados, esticados, desdentados, marinheiros, operários, desocupados. Sem maquiagem, as rugas ficam evidentes.

\section{Uma nota final: diversão como disciplina}

A opção estética e política de Joaquim Pedro de Andrade é a de construir um ídolo que do registro da crônica esportiva passe para o da cultura popular: privilegia um tema visto como menor, segundo Leite Lopes (2006), mas com forte apelo popular e político, o futebol, e dentro dele um dos seus maiores representantes, Garrincha, cuja origem humilde, a condição de ex-trabalhador fabril, a mestiçagem, a afecção aos valores românticos (a família, a simplicidade, a origem, a comunidade, a natureza) são destacadas. A câmera leve, a montagem ágil e não cronológica, a narrativa que mostra o personagem como um "guerrilheiro" que resiste ao trabalho fabril, à tirania das concentrações, às ordens de técnicos e preparadores físicos, contribuem para a composição desse quadro do qual também faz parte a torcida, expressão do "povo". Um público que ocupa as gerais, essa localização térrea de espectadores, sem muita visibilidade, que corresponde aos ingressos mais baratos do estádio. O "povo", na forma das torcidas e no consumo, na identificação gerada pelo espetáculo, surge em sua presença alegre, mas também enigmática, ao ser mostrado na tela: miséria frente aos olhos em close-up, distanciamento que se encolhe não para fazer perder a aura, como explica Benjamin (1977) a respeito das mudanças do conteúdo artístico determinadas pela reprodutibilidade, mas a encontra na beleza e no corpo marcado de cada torcedor, rugas que correspondem às pernas tortas que se mostram aos olhos dos que frequentam as gerais.

Apesar do tom romântico, o documentário encontra algum equilíbrio, como destaca Bentes (1996), ao mostrar o que resta de um personagem entre a ressaca dos títulos e do assédio e os meandros do autoritarismo sobre o futebol. O tom melancólico pouco teria agradado ao patrocinador do projeto, esperançoso em relação a um filme positivo (BENTES, 1996), que 
fizesse elogio à "brasilidade". Dessa armadilha, ainda que o tom romântico prevaleça, o filme escapou.

Resta ainda destacar um importante componente da leitura visual que Joaquim Pedro faz do "povo". O final do filme é anunciado pela saída do Estádio do Maracanã, pelo abandono do lugar consagrado ao êxtase do espetáculo esportivo. A locução acompanha esse movimento, que mostra também os torcedores em massa chegando ao subúrbio, destino do princípio da noite de domingo. Ela diz do ciclo que se fecha para uma nova semana de trabalho que logo se iniciará, culminando em novo domingo de futebol a ser testemunhado. Lazer que acompanha e pontua o ritmo do trabalho, diversão como disciplina, segundo ensinam Horkheimer e Adorno (1997).

\section{Referências}

ADORNO, T. W. Veblens Angriff auf die Kultur. In: Gesammelte Schriften 10-1. Frankfurt am Main: Suhrkamp, 1997, p. 72-96.

BARTHOLO, Tiago Lisboa. Na quadra e no campo: esporte e identidade nacional no Brasil. Dissertação (Mestrado em Educação Física) - Universidade Gama Filho. Rio de Janeiro: UGF, 2007.

BENJAMIN, W. Das Kunstwerk im Zeitalter seiner technischen Reproduzierbarkeit (Erste Fassung). In: . Gesammelte Schriften (I-2). Frankfurt am Main: Surhkamp, 1977.

BENTES, I. Joaquim Pedro: a revolução intimista. Rio de Janeiro: Relume Dumará, 1996.

CARONE NeTtO, M. Metáfora e montagem. São Paulo: Perspectiva, 1974.

CASTRO, R. Estrela solitária: um brasileiro chamado Garrincha. São Paulo: Companhia das Letras, 1995.

DAMO, A. Do dom à profissão: a formação de futebolistas no Brasil e na França. 1. ed. São Paulo: HUCITEC, 2007. v. 1.359 p.

GRAMSCI, A. Quaderni del cárcere. Turim: Einaudi, 1975. (v. 2, 1509 p.).

HORKHEIMER, M.; ADORNO, T. W. Dialektik der Aufklärung. Philosophische Fragmente. In: ADORNO, T. W. Gesammelte Schriften 3. Frankfurt am Main: Suhrkamp, 1997. 
IKEDA, M. A ontologia da montagem como princípio epistemológico: contradições do cinema construtivista de Dziga Vertov. Portal Linguagem do Cinema. LATEC/ UFRJ. Disponível em: <http://www.latec.ufrj.br/linguagemdocinema $>$. Acesso em: 12/10/2009.

LEITE LOPES, J. S. A morte da "alegria do povo". In: MELO, V. A.; ALVITO, M. (Orgs.). Futebol por todo o mundo: diálogos com o cinema. Rio de Janeiro: Editora FGV, 2006. p. 81-114.

LEONE, E. Reflexões sobre a montagem cinematográfica. Belo Horizonte: Editora UFMG, 2005. 276 p.

MELO, V. A. de. Cinema \& esporte: diálogos. Rio de Janeiro: Aeroplano/Faperj, 2006. 138 p.

PEREIRA, L. G.; VAZ, A. F. Le football dans le cinéma nouveau: à propos du film Garrincha, alegria do povo, de Joaquim Pedro de Andrade. In: 15ème Congrès de l'AMSE, 2-6 juin, 2008, Marrakech. Mondialisation et Education: vers une sociéte de la connaissance.

RIAL, C. S. Futebol e mídia: a retórica televisiva e suas implicações na identidade nacional, de gênero e religiosa. Antropolítica, Niterói, v. 14, n. 2, p. 61-80, 2003.

ROCHA, G. Revisão crítica do cinema brasileiro. São Paulo: Cosac \& Naify, 2003. 238p.

VAZ, A. F.; PEREIRA, L. G. Futebol no cinema novo: sobre o filme Garrincha, alegria do povo, de Joaquim Pedro de Andrade. In: Robson Loureiro; Antonio Álvaro Soares Zuin. (Org.). A teoria crítica vai ao cinema. Vitória: EDUFES, 2010. p. $159-176$.

\section{Fonte:}

GARRINCHA, alegria do povo. Direção: Joaquim Pedro de Andrade. Roteiro: Luiz Carlos Barreto, Armando Nogueira, Mário Carneiro, David Neves. Assistente de direção: David Neves. Direção de Fotografia: Mário Carneiro. Montagem: Nello Melli. Narração: Heron Domingues Música: Bach, Frescobaldi, Scarlatti, Prokofiev, Império Serrano, Portela. Produção: L. C. Barreto. LM. 35 mm. P\&B. 70 min. 1963.

Recebido em junho de 2012. Aprovado em julho de 2012. 